\title{
Taurocholate Pool Size and Distribution in the Fetal Rat
}

\author{
J. M. LitTle, J. E. Richey, D. H. VAn Thiel, and R. Lester, Department of Medicine, \\ University of Pittsburgh School of Medicine, Pittsburgh, Pennsylvania 15261
}

\begin{abstract}
A B S TRACT Taurocholate concentrations in fetal and neonatal rats were determined by radioimmunoassay. Total body taurocholate pool size varied from $0.0049 \pm 0.0008$ to $203 \pm 8 \mathrm{nmol} / \mathrm{g}$ body weight from day 5 of gestation to $5 \mathrm{~d}$ after birth. A 50 -fold increase in taurocholate pool size was observed between days 15 and 19 of gestation. The distribution of taurocholate between liver, intestine, and the remainder of the carcass was determined for rats of gestational age $19 \mathrm{~d}$ to $5 \mathrm{~d}$ after birth. The major fraction of total body taurocholate was in the liver and intestine, with $<15 \%$ in the remainder of the carcass. The ratio of taurocholate in intestine to taurocholate in liver, which was 1:17 at $19 \mathrm{~d}$ of gestation, had altered substantially to a ratio of $6: 1$ by $5 \mathrm{~d}$ after birth. Treatment of pregnant rats with $60 \mu \mathrm{g} / \mathrm{d}$ of dexamethasone from gestational day 9 until sacrifice increased fetal taurocholate pool size by $80 \%$ at $15 \mathrm{~d}, 40 \%$ at $19 \mathrm{~d}$, and $16 \%$ at $1 \mathrm{~d}$ after birth. Administration of dexamethasone to the mother also changed the ratio of taurocholate in intestine to taurocholate in liver. At $19 \mathrm{~d}$ of gestation, dexamethasone-treated mothers had fetuses with approximately equal amounts of taurocholate in intestine and liver. This suggested that adrenocorticosteroids stimulate the early maturation of factors controlling taurocholate pool size and tissue distribution in the rat fetus.
\end{abstract}

\section{INTRODUCTION}

It is generally accepted that bile salts play a central role in bile formation and lipid absorption in the adult $(1-3)$. It is only gradually coming to be appreciated, however, that these compounds are of importance to the newborn, and may serve functional roles in the fetus. The fetal development of bile salt synthesis and metabolism has not been completely delineated. Blood, gallbladder, and intestinal bile salt concentrations have been measured in near-term fetuses, premature infants, and newborns $(4-10)$. The gallbladder and intestinal bile salts of fetal and neonatal rabbits have been identified and quantified (11). Bile salt synthesis,

Received for publication 19 September 1977 and in revised form 27 December 1978. secretion, and turnover have been measured in the near-term fetuses of large laboratory animals (12-16). Pool size and synthesis rates have been determined for newborn infants using stable isotope techniques $(17,18)$ or by measuring fecal bile salt excretion $(10,19)$. Excess quantities of bile salt precursors have been identified in the duodenal fluid or excreta of some infants with cholestatic syndromes, and this might suggest the presence of developmental defects of bile salt synthesis $(20-22)$.

Technical factors have precluded a more complete study of the ontogenesis of bile salt metabolism: cost and scarcity have ruled out the use of large laboratory animals, whereas the insensitivity of standard quantitative techniques for bile salt determination have made a study in small laboratory animals impossible.

Recently developed radioimmunoassays $(\text { RIA })^{1}$ for bile salts $(23,24)$ provide the necessary sensitivity for such measurements but are not specific for the taurine conjugates which are predominant in most small animals. We have now developed an RIA for taurocholate, the principle bile salt in rats. The assay is several orders of magnitude more sensitive than gas-liquid chromatography (GLC), is highly specific for taurocholate, and is simple to perform. With this RIA, we have measured the amount and distribution of taurocholate in fetal and neonatal rats, and have examined the effect of maternal adrenocorticosteroid and phenobarbital administration on these parameters.

\section{METHODS}

\section{RIA of taurocholate}

Antigen preparation. Taurocholate and $\left[{ }^{3} \mathrm{H}\right]$ taurocholate purchased commercially (Calbiochem-Behring Corp., American Hoechst Corp., Calif. and New England Nuclear, Boston, Mass.) were shown to be $99 \%$ pure by thin-layer chromatography on silica gel $G$ in three solvent systems. The mixed anhydride of taurocholate was prepared using established techniques (25) by adding $0.4 \mathrm{ml}(1.5 \mathrm{mmol})$ of isobutylchloroformate to a stirred solution maintained at $8^{\circ} \mathrm{C}$, which contained the following constituents: $0.82 \mathrm{~g}(1.5 \mathrm{mmol})$

\footnotetext{
${ }^{1}$ Abbreviations used in this paper: $\mathrm{B} / \mathrm{B}_{0}$, ratio of counts bound at a specific dose level to those bound at zero dose; GLC, gas-liquid chromatography; RIA, radioimmunoassay(s).
} 
taurocholate, $50,000 \mathrm{cpm}\left[{ }^{3} \mathrm{H}\right]$ taurocholate, and $0.75 \mathrm{ml}$ (1.5 mmol) triethylamine in $30 \mathrm{ml}$ dimethylformamide. The reaction was allowed to proceed for $35 \mathrm{~min}$, and the reaction mixture was then added dropwise to a stirred solution containing $2.2 \mathrm{~g}(0.04 \mathrm{mmol})$ bovine serum albumin in $55 \mathrm{ml}$ of $0.04 \mathrm{M} \mathrm{NaOH}$ plus $40 \mathrm{ml}$ dioxane. The newly formed reaction mixture was maintained at $4^{\circ} \mathrm{C}$, at $\mathrm{pH} 9$, with constant stirring for $4.5 \mathrm{~h}$. It was then dialyzed for $48 \mathrm{~h}$ against running cold tap water, and freeze dried. A 25- to 50-mg portion of the freeze-dried bovine serum albumin-taurocholate conjugate was dissolved in $0.1 \mathrm{M} \mathrm{NaOH}$, and aliquots were assayed in a liquid scintillation spectrometer to measure taurocholate binding. The remainder of the freeze-dried conjugate was stored at $-20^{\circ} \mathrm{C}$ until used for stimulation of taurocholate antibody formation.

Antibody formation. The agent used for immunization consisted of the following: $30 \mathrm{mg}$ of bovine serum albumin taurocholate dissolved in $30 \mathrm{ml}$ saline and emulsified with $30 \mathrm{ml}$ of complete Freund's adjuvant and $100 \mathrm{mg}$ of killed Mycobacterium tuberculosis. Female white New Zealand rabbits were injected intracutaneously with $5 \mathrm{ml}$ of the agent at 40 sites, at 2-3 wk intervals. The animals were given $0.5 \mathrm{ml}$ (4 U) of pertussis vaccine (Eli Lilly \& Co., Indianapolis, Ind.) intramuscularly at the time of the initial immunization. Blood samples were obtained from the marginal vein of the ear or by cardiac puncture. These were centrifuged and serum was stored at $-20^{\circ} \mathrm{C}$ until assayed for antibody titer.

Assay procedure. Antibody titers were determined using $500 \mu \mathrm{l}$ of serial dilutions of antiserum, plus $1 \mathrm{ml}$ of diluent buffer (buffer G of Auletta et al. [26]) containing 10,000 cpm of tracer $\left[{ }^{3} \mathrm{H}\right]$ taurocholate $(3.39 \mathrm{Ci} / \mathrm{mmol} \mathrm{sp}$ act $)$. That dilution binding $50 \%$ of added $\left[{ }^{3} \mathrm{H}\right]$ taurocholate was chosen for use in assay procedures. The displacement of bound $\left[{ }^{3} \mathrm{H}\right]$ taurocholate by known amounts of unlabeled taurocholate (0.5-100 pmol) was measured and plotted as a standard curve. Taurocholate in unknown samples was determined as follows: unknowns were incubated with $\left[{ }^{3} \mathrm{H}\right]$ taurocholate, $10,000 \mathrm{cpm}$, in $1 \mathrm{ml}$ of buffer, overnight, at $4^{\circ} \mathrm{C}$. $500 \mu \mathrm{l}$ of antiserum at working dilution was added, and the mixture was incubated for $2 \mathrm{~h}$ at room temperature. Tubes containing only buffer for liquid scintillation spectrometer quench determination, tubes containing buffer and $\left[{ }^{3} \mathrm{H}\right]$ taurocholate for determining nonspecific binding, and tubes containing buffer, $\left[{ }^{3} \mathrm{H}\right]$ taurocholate, and antiserum for measuring binding in the absence of added taurocholate (counts bound at zero dose $\left[\mathrm{B}_{0}\right]$ ) were included in each assay. At the end of a 2 -h incubation, $1.5 \mathrm{ml}$ of cold, saturated $\left(\mathrm{NH}_{4}\right)_{2} \mathrm{SO}_{4}$ was added to each tube, and the tubes were placed on ice for $10 \mathrm{~min}$. They were then centrifuged for $30 \mathrm{~min}$ at $1,000 \mathrm{~g}$, at $4^{\circ} \mathrm{C}$, the supernates were decanted, and the precipitates were washed three times with $50 \%$ saturated $\left(\mathrm{NH}_{4}\right)_{2} \mathrm{SO}_{4}$. The washed precipitates were dissolved in $0.5 \mathrm{ml}$ of $1 \mathrm{M} \mathrm{NaOH}$ and transferred quantitatively to scintillation vials. $1.0 \mathrm{ml}$ of water, $15 \mathrm{ml}$ of aqueous counting medium (Aquasol, New England Nuclear), and $0.2 \mathrm{ml}$ of glacial acetic acid were added to each vial, and after a period of dark and temperature adaptation, samples were counted in a refrigerated Packard liquid scintillation spectrometer (Packard Instrument Co., Inc., Downers Grove, Ill.). Data were analyzed on a Hewlett-Packard 9810 calculator (HewlettPackard Co., Palo Alto, Calif.), and unknown values were calculated from standard curves of logit transforms of the ratio of counts bound at a specific dose level to those bound at zero dose $\left(\mathrm{B} / \mathrm{B}_{0}\right)$ as described by Rodbard et al. (27).

\section{Experimental design}

To determine levels of fetal taurocholate, 200- to 250-g pregnant Wistar rats (Charles River Breeding Laboratories,
Wilmington, Mass.) were sacrificed at 5, 10, 15, 17, 19, 21, and $22 \mathrm{~d}$ after breeding, and newborn rats were sacrificed at 1 and $5 \mathrm{~d}$ after birth. Fetuses through $17 \mathrm{~d}$ gestation were removed from the uterus, weighed, and then homogenized whole in water. At all other ages, liver, gut, and residual carcass were separated, weighed, and then homogenized individually.

The effect of dexamethasone on the accumulation and distribution of taurocholate was studied. Pregnant rats were injected subcutaneously daily with $60 \mu \mathrm{g}$ of dexamethasone dissolved in $0.02 \mathrm{ml}$ of ethylene glycol and $0.98 \mathrm{ml}$ of saline from day 9 of gestation until sacrifice at day 15 or 19 of gestation or $1 \mathrm{~d}$ after birth. A second short-term treatment group was injected with the same dose of dexamethasone for $3 \mathrm{~d}$ before sacrifice. Control animals were injected with the ethylene glycol-saline carrier only.

Comparable studies were conducted in which phenobarbital, $100 \mathrm{mg} / \mathrm{kg}$ per $\mathrm{d}$, dissolved in distilled water, was injected subcutaneously into pregnant rats from gestational day 9 until sacrifice at day 16 or 19 . This dose of phenobarbital induced anesthesia for 10-12 h daily. Food was withheld from control animals during this period. A second group of pregnant rats was injected with $50 \mathrm{mg} / \mathrm{kg}$ per $\mathrm{d}$ for $3 \mathrm{~d}$ before sacrifice on day 19 and compared with suitable controls.

\section{Analytic procedures}

Tissue homogenates, with $800 \mathrm{cpm}\left[{ }^{3} \mathrm{H}\right]$ taurocholate added for recovery determination, were extracted with chloroformmethanol by a modification of the method of Folch et al. (28). The mixture was centrifuged at $1,000 \mathrm{~g}$, the upper phase was transferred to another tube, the proteinaceous interface was washed twice with pure solvent upper phase, and the pooled washes and upper phase were then taken to dryness under $\mathrm{N}_{2}$. The dried residue was dissolved in $1 \mathrm{ml}$ of assay buffer. An aliquot was counted for extraction recovery determination (range, 72-88\%), and the remainder was subjected to taurocholate RIA. To assess the extent of fetal bile salt sulfation, extracts of fetal tissue were assayed by RIA, solvolyzed (29), and then reassayed. Preliminary studies of solvolysis were performed with ${ }^{14} \mathrm{C}$-labeled standards of mono-, di-, and trisulfated taurocholate prepared by the method of Tserng and Klein (30). These established that solvolysis permitted $92 \pm 1.5 \%$ (mean $\pm \mathrm{SEM}$ ) recovery of taurocholate from taurocholate sulfate. When the same standards were added to tissue samples and extracted as usual, the sulfates were quantitatively recovered (95-98\% recovery).

GLC was carried out with a Packard Gas Chromatograph (Packard Instrument Co., Inc.) equipped with flame ionization detectors. Bile acid methyl ester acetates (31) were chromatographed on 2-mm i.d. columns of 2\% OV-210 on 80-100 mesh Gas-Chrom Q (Applied Science Lab, Inc., State College, Pa.) under the following conditions: oven temperature $=240^{\circ} \mathrm{C}$, inlet and detector temperatures $=260^{\circ} \mathrm{C}$, carrier gas flow rate $=40 \mathrm{ml} / \mathrm{min}$. Each sample was analyzed first without, and then with added derivatized lithocholate internal standard. The bile acids in selected samples were also analyzed as the methyl ester trifluoroacetates on columns of $1 \%$ QF-1 (Supelco, Inc., Bellefonte, $\mathrm{Pa}$.) at $215^{\circ} \mathrm{C}$ with similar results except that in these samples $\alpha$-muricholate was not separated from cholate.

\section{RESULTS}

Specificity and sensitivity of the RIA. Based on the binding of the labeled taurocholate which had been added to the reaction mixture, $7 \mathrm{~mol}$ taurocholate $/ \mathrm{mol}$ bovine serum albumin was bound in the protein-hapten 
complex. Rabbits developed measurable antibody titers as early as 1 mo after initiation of immunization. The highest titers (final antiserum dilution of $1 / 400$ in the assay system) were obtained after $\cong 3$ mo of immunization and were maintained with minimal variation for an additional 3-4 mo.

The specificity of the antibody-antigen interaction is summarized in Table I. The results, expressed as the percentage of cross-reaction based on the amount of test material required to displace $50 \%$ of bound $\left[{ }^{3} \mathrm{H}\right]$ taurocholate, show that only other taurine-conjugated bile salts gave significant displacement. Of these, taurocholate monosulfate, taurohyocholate, and taurochenodeoxycholate showed the greatest affinity for the antibody, at 42,19 , and $15 \%$ cross-reactivity, respectively.

A representative standard curve, generated by displacing bound $\left[{ }^{3} \mathrm{H}\right]$ taurocholate with pure, unlabeled taurocholate over a range of $0.5-100 \mathrm{pmol}$, is shown in Fig. 1. The graph on the left (Fig. 1A) is the sigmoid curve typical of RIA in which $\mathrm{B} / \mathrm{B}_{\mathbf{0}}$ (ratio of counts bound at a specific dose level to those bound at zero dose) is plotted against log dose. A logit plot of the same data (Fig. 1B) linearizes the sigmoid curve. The resulting straight line $(r>0.98)$ can be characterized by an equation, which can then be used to determine levels of taurocholate in unknown samples.

To validate the assay and the results, aliquots of fetal tissue bile salt extracts which had been analyzed by

TABLE I

Specificity of Antigen-Antibody Interaction

\begin{tabular}{lc}
\hline \multicolumn{1}{c}{ Test substance } & Cross-reaction \\
\hline & $\%$ \\
Taurocholate monosulfate & 42.1 \\
Taurohyocholate & 19.0 \\
Taurochenodeoxycholate & 14.6 \\
Tauro- $\propto$-muricholate & 7.1 \\
Taurodeoxycholate & 6.2 \\
Taurohyodeoxycholate & 1.6 \\
Taurocholate trisulfate & 1.4 \\
Taurolithocholate & 1.3 \\
Taurocholate disulfate & 0.7 \\
Glycocholate & - \\
Glycochenodeoxycholate & - \\
Glycodeoxycholate & - \\
Cholate & - \\
Chenodeoxycholate & - \\
Deoxycholate & - \\
Lithocholate & - \\
Cholesterol & - \\
Testosterone & - \\
Estradiol & - \\
Taurine & - \\
\hline
\end{tabular}

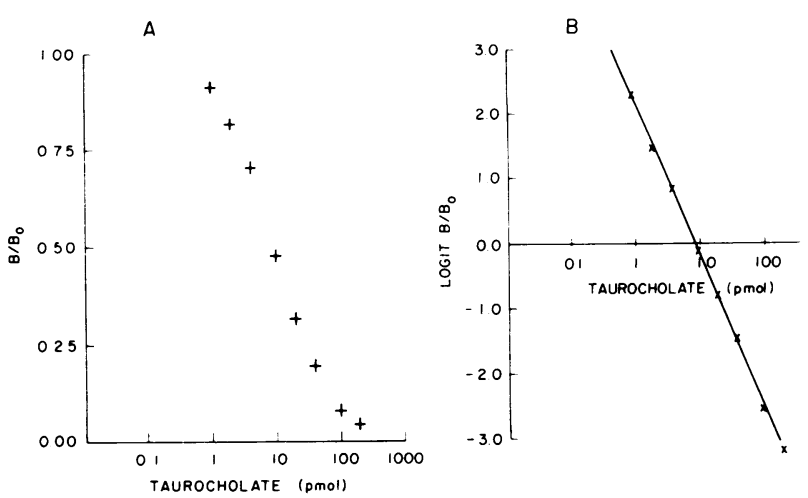

Figure 1 Standard curves for taurocholate RIA. (A) Sigmoid curve resulting from direct graphing of $\mathrm{B} / \mathrm{Bo}$ vs. log dose. (B) Straight line resulting from logit transform of data in $\mathrm{A}$.

RIA were purified, hydrolyzed, and then subjected to GLC on $2 \%$ OV-210 as the methyl ester acetates.

Lithocholate was used as an internal standard after it was determined that it was not present in the fetal extracts and that other commonly used standards (hyodeoxycholate, nordeoxycholate, $5 \beta$-cholanic acid- $3 \alpha$, $7 \alpha$-diol-12-one) were either present in samples or not separated from other peaks. GLC patterns before and after solvolysis were not significantly different. The taurocholate content of each sample as determined by RIA was compared with the amount of cholic acid determined by GLC as shown in Fig. 2. The correlation between the two methods is good with the calculated regression line falling within the $95 \%$ confidence limits of the dotted line representing unity. Measurement of free cholate concentrations in similar hydrolyzed extracts with a cholate antibody in the RIA system confirmed the previously determined taurocholate content of the samples.

Endogenous fetal taurocholate levels. The development of the endogenous taurocholate pool (in nanomoles per gram body weight) in unmanipulated fetal and neonatal rats is shown in Fig. 3. From 5 to 15 d gestation, the levels of taurocholate were barely measurable. The amount increased fourfold on day 17 but still remained below $2 \mathrm{nmol} / \mathrm{g}$ body weight. Between day 17 and 19, the pool increased 13-fold to a level of $25.2 \pm 0.8$ $\mathrm{nmol} / \mathrm{g}$ body weight. From day 19 of gestation through $5 \mathrm{~d}$ after birth, there was a further growth of the taurocholate pool to a final level of $203 \pm 8 \mathrm{nmol} / \mathrm{g}$ body weight.

Taurocholate was measured in tissue extracts by RIA before and after solvolysis. No significant increase in taurocholate was observed. Untreated tissue extracts were subjected to thin-layer chromatography on silica gel $\mathrm{G}$ developed in ethyl acetate-butanol-acetic acidwater $(40: 30: 15: 15)$, to measure the amount of sulfated bile salt present. Less than $5 \%$ of the bile salt pool was in the form of sulfated conjugate. 


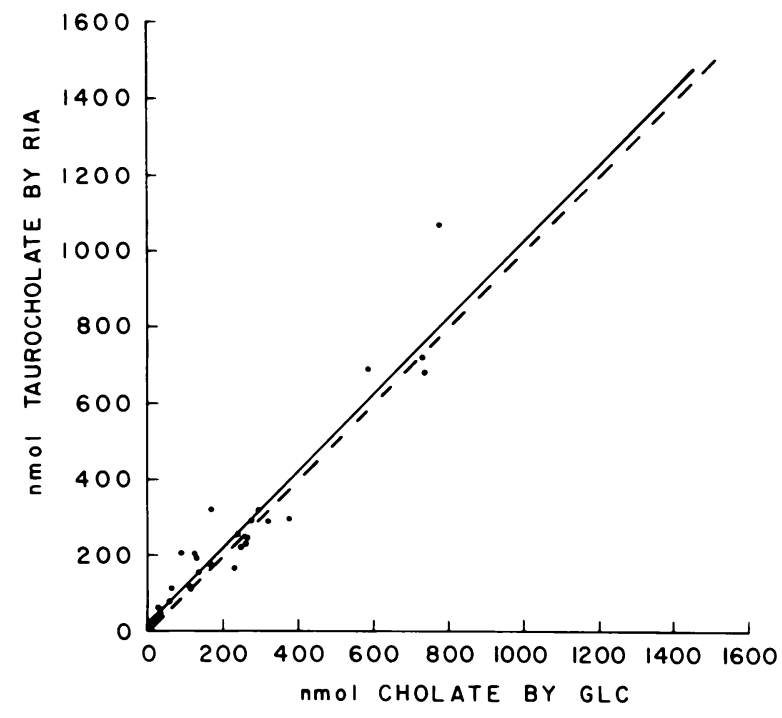

FIGURE 2 Comparison of taurocholate values determined by RIA and cholate values determined by GLC. The dotted line represents unity or absolute correlation of values $(r$ $=1.000)$ and the solid line is the regression line calculated from experimental values $(r=0.953)$.

From gestational day 19 onward, it was possible to assay liver, gut, and carcass separately, and the distribution of the fetal and neonatal taurocholate is shown in Fig. 4. The proportion of taurocholate in liver and gut changed abruptly during the period of observation. At day 19 of gestation, $81 \%$ of the taurocholate pool was found in the liver, whereas the gut contained only $4.5 \%$ and the residual carcass, $14.5 \%$. At day 21, liver and gut contained roughly equivalent amounts of taurocholate (43 vs. $53 \%$ ), and the proportion of taurocholate in the gut continued to increase at each age studied until, at $5 \mathrm{~d}$ after birth, the 19-d level had been essentially reversed with $14.5 \%$ of the pool located in the liver and $83.5 \%$ in the gut. For comparison, five adult rats were assayed for liver, gut, and total taurocholate. Adult taurocholate pool sizes ranged from 101 to $242 \mathrm{nmol} / \mathrm{g}$ body weight, and of the total, 2.9-5.6\% was found in the liver and 90.2$95.4 \%$ in the gut.

It was possible to show by GLC that cholate was the major bile salt present in tissue from gestational day 19 onward. At day 17, however, an average of $54 \%$ of the bile salt pool was chenodeoxycholate and before this, bile salt levels were too minute to be determined by GLC. Thus, because chenodeoxycholate predominated at $17 \mathrm{~d}$ and, in the form of taurochenodeoxycholate, would give a $15 \%$ cross-reaction with the taurocholate RIA, determinations of taurocholate early in gestation represent maximum estimations.

The following bile salts were identified by GLC as being present in fetal and neonatal tissues: cholate, chenodeoxycholate, hyodeoxycholate, $\alpha$-muricholate,

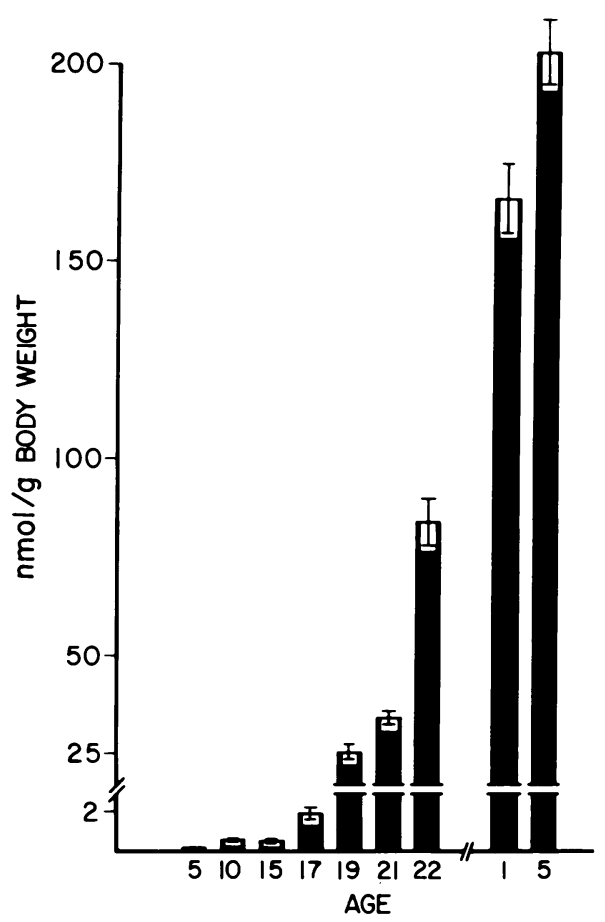

FIGURE 3 Development of fetal and neonatal taurocholate pools. The bars and brackets give the mean \pm SEM of total body taurocholate, in nanomoles per gram body weight, as determined by RIA. The abscissa is the age of the animal, in days gestation for fetuses (to the left of the break in the scale) and in days after birth for neonates (to the right of break).

and $\beta$-muricholate. At day 19 of gestation, all of the aforementioned bile salts were present, the relative proportions being $34,26,7,16$, and $17 \%$, respectively. By $5 \mathrm{~d}$ after birth, however, the bile salt pool included only cholate $(87 \%)$ and $\beta$-muricholate $(13 \%)$ (Fig. 5). Hyocholate which, as a taurine conjugate, has the greatest cross-reaction with the taurocholate antibody in the RIA (other than taurocholate monosulfate), was not identified in any of the fetal samples.

Fetal response to maternal drug administration. Pregnant rats were treated with dexamethasone, 60 $\mu \mathrm{g}$ daily, from day 9 of gestation until sacrifice. Fetal taurocholate pool size is shown in Fig. 6. At each age examined, the taurocholate pool size in animals from dexamethasone-treated mothers was significantly larger than that of control fetuses or neonates. At $15 \mathrm{~d}$, total body taurocholate of dexamethasone-treated rats was $180 \%$, at $19 \mathrm{~d}, 140 \%$, and at $1 \mathrm{~d}$ after birth, $120 \%$ of control values.

The distribution of taurocholate between liver and gut in the two groups was also substantially altered (Fig. 7). At day 19 of gestation, although only $4 \%$ of the taurocholate pool was found in the gut of control fetuses, the gut of steroid-treated fetuses contained $41 \%$. By $1 \mathrm{~d}$ after birth this difference was no longer 


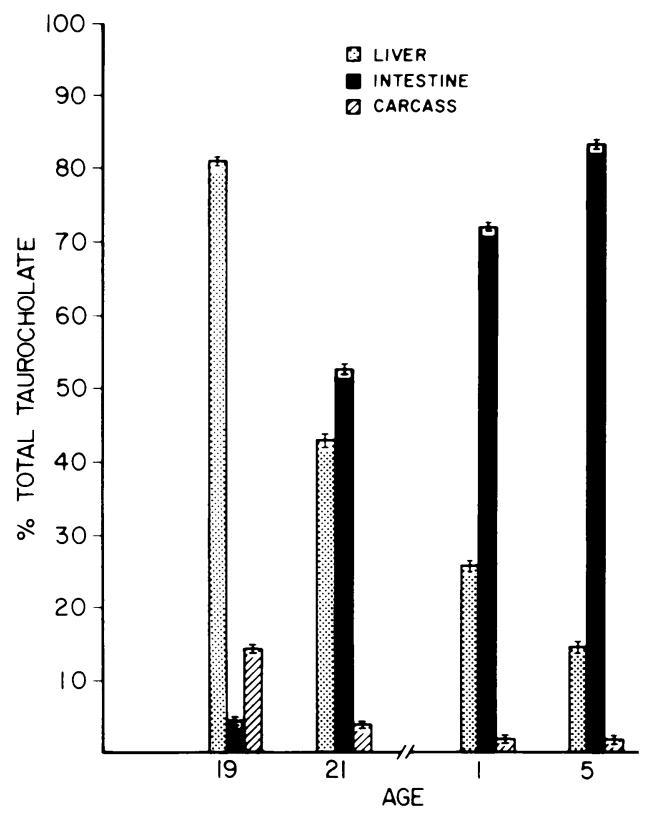

Figure 4 Distribution of fetal and neonatal taurocholate pools. At each age (as in Fig. 3), the mean percent of the total body taurocholate found in liver, intestine, and the residual carcass is represented by a bar, with the brackets giving the SEM.

evident, and the proportions of the pool in liver and gut were essentially equal in steroid-treated and control animals.

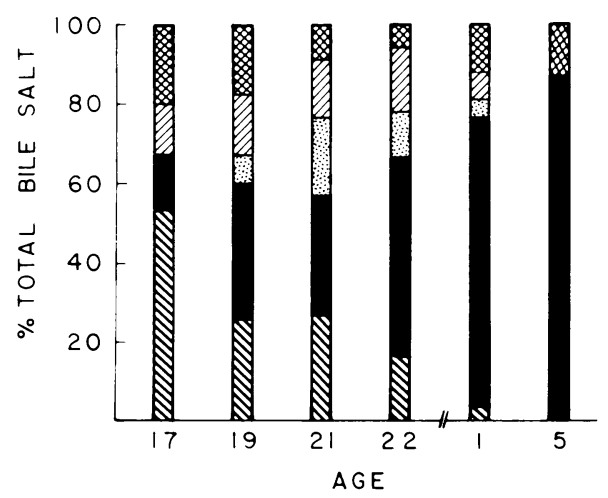

FIGURE 5 Relative composition of fetal and neonatal bile salt pools. At eatch age (Fig. 3), the bar shows the mean percent of the total pool contributed by each individual bile salt ats determined by (BLC (2-12 determinations for each value). It is evident that, with increasing age, the relative proportion of chenodeoxycholate decreases, whereas that of cholate increalses.

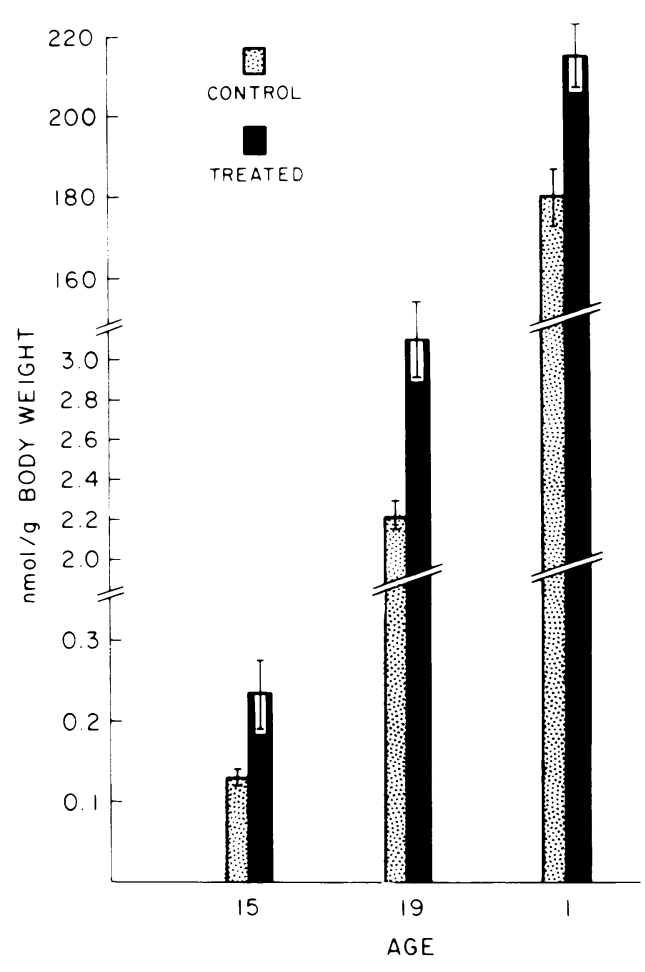

FicicRe 6 Eiffect of matemally administered dexamethasone on fetal and neonatal taurocholate pool size. The stippled bars show mean control values for total body taurocholate. as determined by RIA, and the solid bars give the ecquivalent values from dexamethasone-treated animals. Ages are given as in Fig. 3.

Treatment of pregnant rats with dexamethasone for only 3 d before sacrifice had no effect on the taturocholate pool of $16-d$ fetuses as compared with controls. However, 19-d fetuses from 3-d steroid-treated mothers displared the same patten of bile salt pool expansion, and distribution of that pool between liver and gut, as seen with long-term dexamethasone treatment.

Pregnant rats were treated with phenobarbital. 10() $m g / k g$ per $d$, from dar 9 of gestation until sacrifice. Fetuses of 15 d gestation from phenobarbital-treated mothers had taurocholate pools that were smaller than, but not significantly different from, those

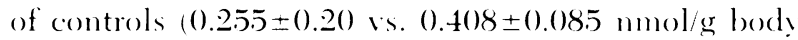
weight respectively; $P>0.1$ ), whereas 19-d phenobarbital-treated fetuses had markedly lower pool sizes than did comparatble controls (0.726 0 (0.04:3 is. 1.9.39 $90.0 .13 \mathrm{nmol} / \mathrm{g}$ bod we whet: $P<0.0(01)$. Treatment with phenobarbital had no effect on the distribution of taurocholate between liver and gut of 19-d fetuses. Total taurocholate and the proportions found in liver and gut were the same in 19-d fetuses from mothers given three injections of phenobarbital $(50) \mathrm{mg} / \mathrm{kg}$ per d) and from control mothers. 


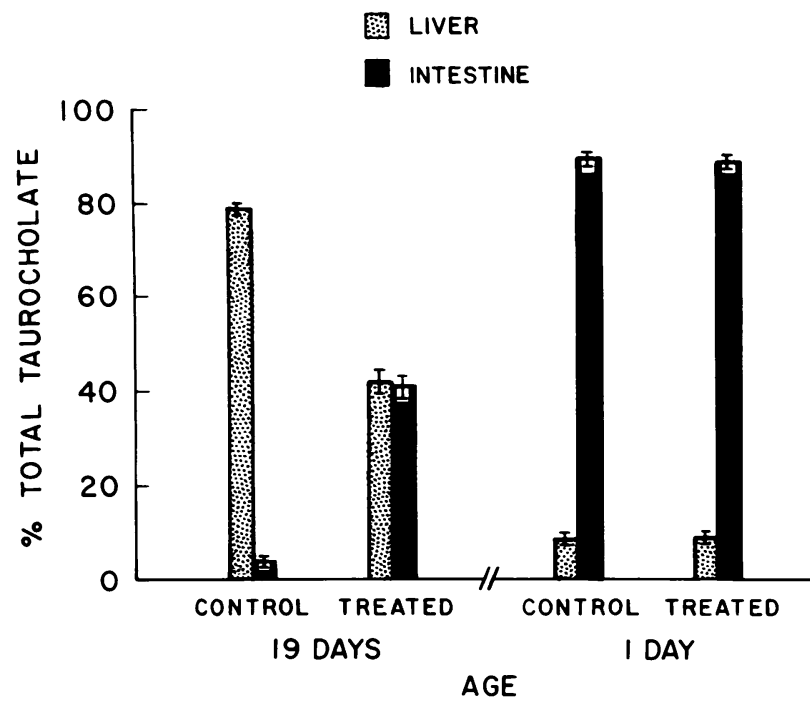

FIGURE 7 Effect of maternally administered dexamethasone on the distribution of fetal and neonatal taurocholate. At each age (see Fig. 3), the mean percent of the total body taurocholate found in liver (stippled bars) and intestine (solid bars) is given for control and dexamethasone-treated animals.

\section{DISCUSSION}

In this study, the rates of accumulation and distribution of taurocholate in the rat fetus and newborn were examined. Where possible, fetal and neonatal bile salts were characterized by GLC, but, in addition, the limits of detection of taurocholate were extended by the development of a RIA relatively specific for this bile salt. Other taurine-conjugated bile salts crossreacted weakly with the assay antibody, and there was no cross-reactivity with glycine conjugates, free bile salts, steroids other than bile salts, or taurine itself. Cross-reactivity with monosulfotaurocholate was observed, but it was shown that sulfated bile salts are a minor fraction of the bile salt pool in the rat fetus and newborn. The RIA was sufficiently sensitive to measure picomole quantities of taurocholate, and thus to quantitate the total body pool size from $5 \mathrm{~d}$ of gestation onward. Intraassay variation equaled $3.0 \%$, and interassay variation equaled 5.4\%. A set of known standards was assayed with each batch of unknowns to insure reproducibility.

The predominant bile salt in adult rat bile is taurocholate (32). Analysis by gas chromatography showed that, although taurochenodeoxycholate was the major fetal bile salt early in gestation, its relative percentage decreased from day 17 onward, and, by gestational day 19, taurocholate predominated. The fact that bile salts were detectable during the first $10 \mathrm{~d}$ of gestation, when the fetal liver is primordial, establishes either that extrahepatic fetal bile salt synthesis occurs early in gestation or, more reasonably, that maternal-fetal bile salt transfer occurs. The latter has been demonstrated using isotopically labeled bile salt in other species (33), and the finding of secondary bile salts in meconium has confirmed the presence of maternal to fetal bile salt transfer (34). Interestingly, in view of the early predominance of taurochenodeoxycholate in the rat fetus, it has been suggested that dihydroxy-bile salts diffuse across the placenta more rapidly than trihydroxy-bile salts (33).

The body pool of taurocholate rose at a slow rate during the first $15 \mathrm{~d}$ of gestation if changes produced solely by increases in body mass were eliminated by expressing the results as amounts per gram body weight. Thereafter, fetal accumulation of taurocholate accelerated markedly. During the period between gestational day 15 and 19 , a 50 -fold increase in taurocholate pool size was observed. Taurocholate pool size continued to increase through the remainder of gestation, and into the first $5 \mathrm{~d}$ of life, but at progressively diminishing rates. At $5 \mathrm{~d}$, taurocholate pool size equaled $203 \pm 8 \mathrm{nmol} / \mathrm{g}$ body weight, eight times the pool size measured at $19 \mathrm{~d}$.

The observations on the changes in fetal taurocholate pool size are compatible with several hypotheses. The rapid period of pool size expansion between days 15 and 19 coincides with the period of development of the fetal hepatic enzymatic apparatus for taurocholate synthesis (35). Taurocholate synthesis is demonstrable in rat fetal hepatic organ culture explants from fetuses of gestational age $17 \mathrm{~d}$ and onward (36). Thus, it is possible that increased taurocholate accumulation reflects the onset of fetal hepatic taurocholate synthesis.

By gestational day 19, the fetal organs were found to be of sufficient size and consistency to permit the separation of liver, gut, and the remainder of the carcass. From day 19 onward $>85 \%$ of the taurocholate pool was confined to the gut and liver. At day 19 the gut contained $<1 / 17$ th as much taurocholate as the liver, by day 21 the amounts of taurocholate in the gut and liver were approximately equal, and $5 \mathrm{~d}$ after birth the gut contained six times as much taurocholate as the liver. When these parameters were measured in the adult, it was found that the intestine contained $\cong 20$ times as much taurocholate as the liver. Thus, the direction of change of neonatal taurocholate distribution was toward, but not to the adult pattern.

Relocation of the primary site of the taurocholate pool from the liver to the gut is compatible with several interpretations. Direct entry of taurocholate from the plasma to the gut lumen might occur, but previous experience suggests that this process is minimal (13), and uphill transport would have to be hypothesized to account for the observed concentrations. Increased hepatobiliary secretion or decreased intestinal reabsorption might account for the redistribution of 
taurocholate. Previous studies have established that the fetal gut is relatively permeable to taurocholate, and there is no evidence to suggest that this process changes significantly during the last third of gestation (37). Inevitably, the early finding of taurocholate accumulations in the liver, and the progressive relocation of taurocholate into the intestine suggests that taurocholate secretion begins during the period between 19 and $21 \mathrm{~d}$ of gestation and continues to develop during late gestation and the first days after birth. These findings are consistent with the histologic changes of canalicular proliferation and maturation which are observed during the late fetal and early neonatal periods $(38-40)$.

Glucocorticoids produce an early increase in taurocholate pool size, and a redistribution of taurocholate to the intestine. Glucocorticoids induce the early maturation of a variety of hepatic enzymatic systems (41), and stimulate the appearance of bile canaliculi in cell cultures of fetal rat hepatocytes $(42,43)$. Bile salt synthesis and secretion are stimulated 20 -fold in vitro by the addition of $1 \mu \mathrm{M}$ cortisol to the medium of fetal hepatic organ cultures (36). A retrospective clinical study suggested that the administration of glucocorticoids to the mother during the last week of gestation increases bile salt pool size and synthesis rate in premature infants (18). It is, thus, possible that the changes in fetal pool size and distribution observed in association with maternal glucocorticoid administration were the result of changes induced in fetal hepatic synthesis and secretion of taurocholate.

No alteration in taurocholate pool size or distribution was produced by the administration of phenobarbital to the mother. Phenobarbital is known to cross the placenta of the rat (44). It has been shown previously, however, that in certain species of rats phenobarbital fails to induce the growth of hepatic endoplasmic reticulum in fetuses (44). It appears, therefore, that in the fetal rat, phenobarbital fails to produce changes in bile acid metabolism comparable to those produced by glucocorticoid.

\section{ACKNOWLEDGMENTS}

The authors wish to thank Dr. W. H. Elliott and Dr. R. Shaw, St. Louis University for their gift of tauro- $\propto$-muricholate for use in calibration of the taurocholate RIA.

This work was supported in part by U. S. Public Health Service grants HD 08954, AMHD 17847, and AM 07138.

\section{REFERENCES}

1. Hofmann, A. F., and D. M. Small. 1967. Detergent properties of bile salts: correlation with physiological function. Annu. Rev. Med. 18: 333-376.

2. Bergstrom, S., and H. Danielsson. 1968. Formation and metabolism of bile acids. Handb. Physiol. 5(Sect. 6): 2391-2407.
3. Hofmann, A. F. 1968. Function of bile in the alimentary canal. Handb. Physiol. 5(Sect. 6): 2507-2533.

4. Norman, A., B. Strandvik, and O. Ojamae. 1972. Bile acids and pancreatic enzymes during absorption in the newborn. Acta Paediatr. Scand. 61: 571-576.

5. Encrantz, J. C., and J. Sjovall. 1959. On the bile acids in duodenal contents of infants and children. Bile acids and steroids. 72. Clin. Chim. Acta. 4: 793-799.

6. Poley, J. R., J. C. Dower, C. A. Owen, Jr., and G. B. Stickler. 1964. Bile acids in infants and children. $J$. Lab. Clin. Med. 63: 838-845.

7. Bongiovanni, A. M. 1965. Bile acid content of gallbladder of infants, children and adults. J. Clin. Endocrinol. Metab. 25: 678-685.

8. Challacombe, D. N., S. Edkins, and G. A. Brown. 1975. Duodenal bile acids in infancy. Arch. Dis. Child. 50: 837-843.

9. Sandberg, D. H. 1970. Bile acid concentrations in serum during pregnancy and childhood. Pediatr. Res. 4: 262267.

10. Signer, E., G. M. Murphy, S. Edkins, and C. M. Anderson. 1974. Role of bile salts in fat malabsorption of premature infants. Arch. Dis. Child. 49: 174-180.

11. Subbiah, M. T. R., L. Marai, D. M. Dinh, and J. W. Penner. 1977. Sterol and bile acid metabolism during development. 1. Studies on the gallbladder and intestinal bile acids of newborn and fetal rabbit. Steroids. 29: 83-92.

12. Peric-Golia, L., and H. Socic. 1968. Biliary bile acids and cholesterol in developing sheep. Am. J. Physiol. 215: 1284- 1287 .

13. Jackson, B. T., R. A. Smallwood, G. J. Piasecki, A. S. Brown, H. F. J. Rauschecker, and R. Lester. 1971. Fetal bile salt metabolism. I. The metabolism of sodium cholate $-{ }^{14} \mathrm{C}$ in the fetal dog. J. Clin. Invest. 50: 1286- 1294 .

14. Smallwood, R. A., R. Lester, G. J. Piasecki, P. D. Klein, R. Greco, and B. T. Jackson. 1972. Fetal bile salt metabolism. II. Hepatic excretion of endogenous bile salt and of a taurocholate load. J. Clin. Invest. 51: 1388-1397.

15. Little, J. M., R. A. Smallwood, R. Lester, G. H. Piasecki, and B. T. Jackson. 1975. Bile salt metabolism in the primate fetus. Gastroenterology. 69: 1315-1320.

16. Smallwood, R. A., P. Jablonski, and J. McK. Watts. 1974. Bile acid synthesis in the developing sheep liver. Clin. Sci. Mol. Med. 45: 403-406.

17. Watkins, J. B., D. Ingall, P. Szczepanik, P. D. Klein, and R. Lester. 1973. Bile salt metabolism in the newborn. Measurement of pool size and synthesis by stable isotope technic. N. Engl. J. Med. 288: 431-434.

18. Watkins, J. B., P. Szczepanik, J. B. Gould, P. Klein, and R. Lester. 1975. Bile salt metabolism in the human premature infant. Preliminary observations of pool size and synthesis rate following prenatal administration of dexamethasone and phenobarbital. Gastroenterology. 69: 706-713.

19. Roy, C. C., M. Ste-Marie, L. Chartrand, A. Weber, H. Bard, and B. Doray. 1975. Correction of the malabsorption of the preterm infant with a medium-chain triglyceride formula. J. Pediatr. 86: 446-450.

20. Eyssen, H., G. Parmentier, F. Compernolle, J. Boon, and E. Eggermont. 1972. Trihydroxycoprostanic acid in the duodenal fluid of two children with intrahepatic bile duct anomalies. Biochim. Biophys. Acta. 273: 212-221.

21. Hanson, R. F., J. N. Isenberg, G. C. Williams, D. Hachey, P. Szczepanik, P. D. Klein, and H. L. Sharp. 1975. The metabolism of $3 \propto, 7 \propto, 12 \propto$-trihydroxy-5 $\beta$ cholestan-26-oic acid in two siblings with cholestasis 
due to intrahepatic bile duct anomalies. An apparent inborn error of cholic acid synthesis. J. Clin. Invest. 56: $577-587$.

22. Makino, I., J. Sjovall, A. Norman, and B. Strandvik. 1971. Excretion of $3 \beta$-hydroxy-5-cholenoic and 3-hydroxy$5 \alpha$-cholanoic acids in the urine of infants with biliary atresia. FEBS (Fed. Eur. Biochem. Soc.) Lett. 15: $161-164$.

23. Simmonds, W. J., M. G. Korman, V. L. W. Ko, and A. F. Hofmann. 1973. Radioimmunoassay of conjugated cholyl bile acids in serum. Gastroenterology. 65: 705-711.

24. Demers, L. M., and G. Hepner. 1976. Radioimmunoassay of bile acids in serum. Clin. Chem. 22: 602-606.

25. Erlanger, B. F., F. Borik, S. M. Beiser, and S. Lieberman. 1959. Steroid-protein conjugates. II. Preparation and characterization of conjugates of bovine serum albumin with progesterone, dehydrocorticosterone, and estrone. J. Biol. Chem. 234: 1090-1094.

26. Auletta, F. J., B. V. Caldwell, and G. L. Hamilton. 1974. Androgens: testosterone and dehydrotestosterone. In Methods of Hormone Radioimmunoassay. B. M. Jaffe and H. R. Behrman, editors. Academic Press, Inc., New York. 364 pp.

27. Rodbard, D., W. Bridson, and P. L. Rayford. 1969. Rapid calculations of radioimmunoassay results. J. Lab. Clin. Med. 74: 770-781.

28. Folch, J., M. Lees, and G. H. Sloane-Stanley. 1957. A Simple method for the isolation and purification of total lipides from animal tissue. J. Biol. Chem. 226: 497-509.

29. Palmer, R. H., and M. G. Bolt. 1971. Bile acid sulfates. I. Synthesis of lithocholic acid sulfates and their identification in human bile. J. Lipid Res. 12: 671-679.

30. Tserng, K-Y., and P. D. Klein. 1977. Synthesis of sulfate esters of lithocholic acid, glycolithocholic acid and taurolithocholic acid with sulfur trioxide-triethylamine. J. Lipid Res. 18: 491-495.

31. Roovers, J., E. Evrard, and H. Vanderhaeghe. 1968. An improved method for measuring human blood bile acids. Clin. Chim. Acta. 19: 449-457.

32. Subbiah, M. T., A. Kuksis, and S. Mookerjea. 1969. Secretion of bile salts by intact and isolated rat livers. Can. J. Biochem. 47: 847-854.
33. Lester, R., J. M. Little, R. Greco, G. H. Piasecki, and B. T. Jackson. 1972. Fetal bile salt formation. Pediatr. Res. 6: 375. (Abstr.)

34. Sharp, H. L., J. Peller, J. B. Carey, Jr., and W. Krivit. 1971. Primary and secondary bile acids in meconium. Pediatr. Res. 5: 274-279.

35. Danielsson, H., and W. J. Rutter. 1968. The metabolism of bile acids in the developing rat liver. Biochemistry. 7: 346-352.

36. Lester, R., J. M. Little, R. C. deBelle, N. R. Blacklow, and D. H. Van Thiel. 1977. Cortisol stimulates fetal bile salt synthesis in vitro. Gastroenterology. 72: 1088. (Abstr.)

37. Lester, R., R. A. Smallwood, J. M. Little, A. S. Brown, G. J. Piasecki, and B. T. Jackson. 1977. Fetal bile salt metabolism. The intestinal absorption of bile salt. $J$. Clin. Invest. 59: 1009-1016.

38. Wood, R. L. 1965. An electron microscope study of developing bile canaliculi in the rat. Anat. Rec. 151: 507-512.

39. De Wolf-Peeters, C., R. DeVos, and V. Desmet. 1972. Electron microscopy and histochemistry of canalicular differentiation in fetal and neonatal rat liver. Tissue Cell. 4: $379-388$.

40. De Wolf-Peeters, C., R. DeVos, and V. Desmet. 1971. Histochemical evidence of a cholestatic period in neonatal rats. Pediatr. Res. 5: 704-709.

41. Greengard, O. 1970. The development formation of enzymes in rat liver. In Biochemical Actions of Hormones. G. Litwack, editor. Academic Press, Inc., New York. 53-87.

42. Lambiotte, M., A. Vorbrodt, and E. L. Benedetti. 1973. Expression of differentiation of rat foetal hepatocytes in cellular culture under the action of glucocorticoids: appearance of bile canaliculi. Cell Differ. 2: 43-53.

43. Billet, C., C. Plas, and R. Jacquot. 1972. Etude en microscopie électronique d'hépatocytes foetaux de rat en culture primaire: action du cortisol. C. R. H. Acad. Sci. 274: 2338-2340.

44. Chedid, A., and V. Nair. 1974. Ontogenesis of cytoplasmic organelles in rat hepatocytes and the effect of prenatal phenobarbital on endoplasmic reticulum development. Dev. Biol. 39: 49-62. 